\title{
The Role of Potato Seed Cooperative on the Livelihood of Rural Households in Ethiopia
}

\author{
Wegayehu Bogale Fitawek (Corresponding author) \\ Department of Agricultural Economics, Extension and Rural Development, University of \\ Pretoria, 0002, South Africa \\ E-mail:wegbogale@gmail.com \\ Belaineh Legesse \\ School of Agricultural Economics and Agribusiness Management, Haramaya University, \\ 138, Dire Dawa, Ethiopia \\ E-mail: belaineh.legesse@gmail.com
}

Received: July 26, 2017

doi:10.5296/jas.v6i4.11598
Accepted: March 8, 2018

URL: https://doi.org/10.5296/jas.v6i4.11598

\begin{abstract}
Agricultural Cooperatives help their members to increase their yield and incomes by pooling their resource to support collective service provisions and economic empowerment. The objective of this paper is to provide empirical evidences of the impact of potato seed producing cooperatives on the livelihoods of rural households in the study area. The study has used cross-sectional data of year 2013. Primary data were collected from the sample of 172 households (82 from Haramaya and 90 from Kersa districts) from both members of cooperative and non-member. A propensity score matching method was used to evaluate the impact of potato seed producing cooperative on household income, expenditure and asset. The evaluation results revealed that member of potato seed production cooperative have got higher income from crop production, total annual income and asset holdings amounting to Birr 29 006, 33901 and 47768 respectively. Members also spent Birr 11728 more than non-member households. This indicates membership to potato seed cooperative is found to have a positive and significant on livelihood indicators. Therefore, the government and other non-government organization like ISSD should provide more support to expand seed producing cooperative to improve the livelihood and food security statues of the rural households.
\end{abstract}

Keywords: potato seed, impact, livelihood, logistic regression, propensity score matching 


\section{Introduction}

Agriculture in Ethiopia is the foundation of the country's economy. It contributes over 38.8\% of gross domestic product (GDP), 83.9\% of exports and $80 \%$ of total employment. Generation and transfer of new technologies are critical for agricultural development. Seed is the foundation of every agriculture production value chain (Dawit et al., 2010). Consequently, improved varieties are an essential input for increasing crop productivity. However, most farmers in Ethiopia still do not have a sustainable access to improved and quality seed. Furthermore, many of the released varieties have never been widely disseminated to the growers (Hirpa et al., 2012).

In Ethiopia, there are four seed production systems, namely, informal, community-based, formal and commercial seed systems. The informal seed system consists of self-saved seed or farmer-to- farmer seed exchange. It accounts for $80-90 \%$ of the seed used by smallholder farmers (Amsalu et al., 2014). Whilst, the formal seed system is made of Ministry of Agriculture and Rural development (MoARD), Ethiopia Agricultural Research Institute (EARI), Ethiopia Seed Enterprise (ESE) and Regional Seed Enterprises. The formal system is critically involved in breeding, producing and releasing different varieties of seeds (breeder seeds, pre-basic and basic seeds). On the other hand, cooperative unions, private sector and other organizations are heavily engaged in multiplication of certified seeds. Despite having several players in the seed system, the gap between improved seed demand and supply remain alarming (Dawit, 2011).

Like other developing economies, Ethiopia recommends collective actions as a solution to promote income distribution, reduce poverty and vulnerability, and improve quality of life and social welfare. Cooperative and agricultural unions play an increasingly central role in importing, packaging and distributing chemical fertilizer and other inputs throughout the country. Since 1960s, Ethiopia has been promoting cooperatives as a mechanism to enhance the development of small scale agriculture (Bezabih, 2012). In September 2010, Ethiopia developed a five year Growth and Transformation Plan (GTP) 2010-2015 that significantly highlighted the agricultural sector as the main existing engine of the economy. Notwithstanding, the GTP envisioned that investments in the agriculture would transform the industry sector to be the main engine of the economy. Henceforth, agricultural and rural development strategy underscores the role of cooperatives to attainment of sustainable food security and economic development.

Agricultural cooperatives are very important to help farmers to increase their yield and incomes by pooling their resource together and support collective service provisions. Accordingly, cooperatives in Ethiopia have developed a number of interventions such as provision of agricultural input and output marketing, facilitation of irrigation for crop production, value addition, creation of employment, and lastly establishment of small and micro enterprises (Veerakumaran, 2007). Furthermore, agriculture cooperatives provide farmers with inputs while ensuring members' social cohesion and economic improvement (ATA, 2012). Minilek et al. (2012) argue seed producer cooperatives uplift the living conditions of farmers and communities through provision of basic seed to the farmers which are high yielding and marketable varieties.

Potato is one of the most important tuber crops grown in Ethiopia and a high potential crop to 
improve food security. In East Hararghe, farmers have relatively longer history of using improved potato seed. However, lack of high-quality potato seed is the most important factor for the low area coverage and low productivity. Farmers produce one third (11-13 metric tons $\mathrm{ha}^{-1}$ ) of the potential production (30-40 metric tons ha ${ }^{-1}$ ) (Hirpa et al., 2012). This is attributed to lack of improved varieties and use of poor quality propagation material by farmers. Consequently, Ethiopia launched the Integrated Seed Sector Development (ISSD) programme in conjunction with Food and Agricultural Organization and the Royal Netherlands Embassy to improve seed shortage in the country. Furthermore, The ISSD through the Local Seed Business (LSBs) project facilitates the transition from farmer to community or cooperative-based seed production towards a formal commercial approach seed production (Fitsum et al, 2006). However, no study has been conducted to assess the impact of potato seed production cooperatives on the livelihoods of the member households.

It is against this background that this paper would like to provide empirical evidences on impacts of seed producing cooperative on the livelihoods of rural households in the study areas. Accordingly, we pose two researchable questions, viz., (i) What factor combinations determine household participation in the cooperatives? (ii) Do households that are member to cooperatives have higher incomes? This paper consists of the following sections. Section one contains introduction and brief history of cooperative in Ethiopia. Section two describes materials and methods that used to analyse the impact of cooperative. Section three presents empirical results and discussion. Finally, the paper closes with concluding remarks in section four.

\subsection{History of Cooperatives in Ethiopia}

Ethiopia is one of the country, which has amusing indigenous institutions that organized to solve social and economic problems. These organizations/institutions encourage mutual benefits and have democratic and open structure and voluntary formation. They have rules and regulations, which all members should follow and the leaders often work on voluntary basis. Edir" is one of the main indigenous institutions, mainly gives services on funeral ceremonies and they provide financial and other support for the late family. The source of income to accomplish these services is come from member's monthly contribution. Currently, most Edir has legal status and they started evolved on providing social services like credit (Veerakumaran, 2007). The other indigenous institutions in Ethiopia is "Equb", which is informal form of saving and credit organization. It organized by a group of people with more or less similar earning position, the leader of the group collect equal amount of money on a cyclic basis so that each one of them receives one period's contribution on a rotational basis. This is good practice of saving, rather members use the money to solve their immediate economic and social problems (Veerakumaran, 2007). The other indigenous institution is "Debo or Wenfel or Guza", which is limited to the rural areas where people living in the nearby areas pull their labour and other working capital such as oxen and farm equipments to perform agricultural activities in a rotation manner.

The modern form of cooperative in Ethiopia was established in the 1960s (MoARD, 2002). During this time, cooperative societies were guided under the free market system. Whereas, membership was limited to the landlords that produce and deliver industrial crops. However, during the military regime, cooperatives were used as a political tool; and members lacked 
real benefits and sense of ownership. The Federal Government of Ethiopia were first refreshed cooperatives by proclamation No. 85/1994 and later by the more comprehensive "Cooperative Societies Proclamations No.147/1998" and 402/2004 are the bases of the present day cooperatives strength ((FDRE, 2002; Tadesse, 2006).

Seed producer cooperatives, as economic enterprises play a great role in improving the socioeconomic conditions of their members and their local communities through addressing the problem of food insecurity by provision of basic seed to farmers which are high yielding and marketable varieties. Formal seed producer cooperative started in Ethiopia before 10 years by organizing informal seed producer groups in collaboration with governmental and non-governmental organizations. Informal seed producer groups were functioning without a legal ground and vision, mission and strategic plans. Therefore to increase a supply of seed in accountable and sustainable manner legal groups became important and seed producer cooperatives did emerge (Minilek et al., 2012). Since 2009 a number of seed producers and marketing cooperatives have been established in different parts of the country following the support provided by the local seed business project and other partners.

\section{Materials and Methods}

\subsection{Methods of Data Collection}

In this paper, we collected both primary and secondary data (qualitative and quantitative data). The primary data was collected through randomised household survey from both members and non-members of seed producer cooperatives. The study used structured and semi-structured questionnaires (formal sample survey) to collect primary data. Secondary data was compiled from published and unpublished sources. A three stage stratified random sampling procedure was used in both districts. In the first stage, Haramaya and Kersa districts were purposively selected based on potential potato production; next one Kebele was purposively selected from each district based on availability of matured improved potato seed producer cooperative (Tinke from Haramaya and Ifa Jalala from Kersa the others are newly established ones). In the third stage, 172 representative households (82 from Tinike and 90 from Ifa Jalala) were randomly selected for interview from the two strata.

The data was analyzed using both descriptive and inferential statistical tools. The precise econometrics model to analyze impact or quantify the effect of a certain treatment is Difference-In-Difference (DID) method, but due to lack of the base line data, Propensity Score Matching (PSM) was used in this paper with the view of comparing the comparable using the counter-factual data. We used STATA Software to analyse the available data.

\subsection{Mathematical Specifications of PSM Method}

Rosenbaum and Rubin (1983) first developed propensity Score Matching (PSM). This technique was widely applied as a social program evaluators for the last twenty five years (Jalan and Ravallion, 2003; Dehejia and Wahba, 2002). The propensity score matching (PSM) technique enables us to extract from the sample of non-participating households a set of matching households that look like the participating households in all relevant pre-intervention characteristics. In other words, PSM matches each participant household with a non-participant household that has almost the same likelihood of participating into the program. This study also applies a propensity score matching technique to analyses the 
average treatment effect on the treated (member) group.

In this study, we used a Logit model to estimate Propensity Scores for each observation. The advantage of this model is that the probabilities are bounded between 0 and 1 . The dependent variable is dichotomous, taking two values, 1 if a member of cooperative and 0 otherwise. The outcome variables are income from crop, income from livestock, total household annual income and household asset holding. The independent variables are both continuous and categorical. After obtaining the predicted probability values, conditional on the observable covariates (the propensity scores) from the binary estimation, matching was done using a matching algorithm that was selected based on the data at hand.

According to Gujarati (2004) the mathematical formula of logit model is:

$$
\mathrm{P}_{\mathrm{i}}=\frac{e^{\mathrm{Z}_{\mathrm{i}}}}{1+e^{z_{i}}}
$$

Where, $P_{i}$ is the probability of participation for the $i^{\text {th }}$ household and it ranges from $0-1$

$\mathrm{Z}_{\mathrm{i}}$ is a function of $\mathrm{n}$-explanatory variables which is also expressed as:

$\mathrm{Z}_{\mathrm{i}}=\mathrm{B}_{0}+\sum \mathrm{B}_{\mathrm{i}} \mathrm{X}_{\mathrm{i}}+\mathrm{U}_{\mathrm{i}}$

$\mathrm{i} \quad=1,2,3, \ldots, \mathrm{n}$

$\mathrm{B}_{0}=$ intercept

$\mathrm{B}_{\mathrm{i}}=$ regression coefficients to be estimated or logit parameter

$\mathrm{U}_{\mathrm{i}}=\mathrm{a}$ disturbance term, and

$\mathrm{X}_{\mathrm{i}}=$ participating households' characteristics

According to Gujarati (2004), the coefficient of the logistic model result can be write in terms of the odds and $\log$ of odd ratio. The odds ratio indicates the ratio of the probability that an individual will be participant $\left(\mathrm{P}_{\mathrm{i}}\right)$ to the probability that individual will not participant $\left(1-\mathrm{P}_{\mathrm{i}}\right)$.

The formula of the probability that a household goes to non participant is:

$$
1-\mathrm{P}_{\mathrm{i}}=\frac{1}{1+e^{z_{i}}}
$$

Therefore, using equation (1) and (2) the odds ratio can be written as:

$$
\frac{P_{i}}{1-P_{i}}=\frac{1+e^{z_{i}}}{1+e^{-z_{i}}}=e^{z_{i}}
$$

Where, $\frac{P_{i}}{1-P_{i}}$ is shows the odds ratio in favor of participating in cooperative. It is the ratio of the probability that a household would participate in the cooperative to the probability that he/she would not participate in the cooperative. Finally, taking the natural logarithms of the odds ratio of equation (3) will give the logit model as indicated below. 


$$
\mathrm{Z}_{\mathrm{i}}=\ln \left(\frac{\boldsymbol{P}_{(i)}}{\mathbf{1}-\boldsymbol{P}_{(i)}}\right)=\ln \left[e^{\boldsymbol{\beta}_{\circ}+i \sum_{i=1}^{m} B i X i}\right]
$$

Where: $Z_{i}$ - is a function of $n$ explanatory variables $\left(X_{i}\right)$ which is also expressed as:

$$
Z_{i}=\beta_{0}+\beta_{1} X_{1}+\beta_{2} X_{2}+\ldots+\beta_{n} X_{n}
$$

Where: $\beta_{0}$, is an intercept, $\beta_{1}, \beta_{2} \ldots, \beta_{\mathrm{n}}$ are slopes of the equation in the model. $L_{i}$ is log of the odds ratio, which is not only linear in $\mathrm{X}$ but also linear in the parameters. $\mathrm{X}_{\mathrm{i}}$ is vector of explanatory variables.

However, the most prominent evaluation parameter is the so-called Average Treatment Effect on the Treated (ATT), which focuses explicitly on the effects on those for whom the program is actually intended (members in this paper) and it was given by:

$$
\tau_{\mathrm{ATT}}=\mathrm{E}(\tau / \mathrm{D}=1)=\mathrm{E}\left(\mathrm{Y}_{1} / \mathrm{D}=1\right)-\mathrm{E}\left(\mathrm{Y}_{0} / \mathrm{D}=1\right)
$$

Where: $\mathrm{E}\left(\mathrm{Y}_{1} / \mathrm{D}=1\right)$ are data of cooperative members.

\subsection{Steps of Propensity Score Matching Method}

Four steps were accomplished before practiced matching tasks. Firstly, we estimated values of program participation (propensity scores) for all households, member of the cooperative and non-member of cooperative. Then over-lap condition was tested by using common support condition on the propensity score distributions of household with and without participation to the cooperative. Thirdly, we tried to discarded observations whose predicted propensity scores fall outside the range of the common support region. Finally, sensitivity analysis was made in order to check whether the hidden bias affects the estimated ATT or not (robustness of the estimation).

\section{Propensity Score Matching Results}

\subsection{Propensity Score Estimation}

Propensity scores were estimated using binary logistic regression to match cooperative member households and non-member households based on the observed characteristics. The logistic regression output shows that six variables were statistically significant at different probability levels (Table 1). From data gathering from both districts, variables such as experience in potato seed production, cultivated land holding, accessibility of social network, availability of irrigation equipment and district dummy are statistically significant at $1 \%$ significance level. In addition, total livestock unit is statistically significant at 5\% significance level. This means, those farmers that have more experienced in potato seed production, higher number of livestock holding, larger size of cultivated land, higher access of social network, and availability of more irrigation equipment have high chance to join seed producer cooperative. In this study the result of district dummy was also significant. This shows that there is a significance difference on membership participation between the two districts. The probability to be a member in Kersa was higher than in Haramaya district (Table 1). 


\section{Macrothink}

Table 1. The logistic regression model estimation

\begin{tabular}{lllll}
\hline Variable & Coefficients & Std. & Z- values & dy/dx \\
\hline SEX & -1.197 & 0.776 & -1.54 & -0.274 \\
EDU & -0.058 & 0.522 & -0.11 & -0.014 \\
FAMS & -0.007 & 0.119 & -0.06 & -0.002 \\
EXPR & 0.369 & 0.082 & $4.49^{* * *}$ & 0.092 \\
TLU & 0.299 & 0.146 & $2.05^{* *}$ & 0.075 \\
TLH & 1.148 & 0.414 & $2.77^{* * *}$ & 0.287 \\
SOCN & 2.634 & 0.582 & $4.52^{* * *}$ & 0.577 \\
EXPEC & 0.747 & 0.624 & 1.19 & 0.186 \\
IRREQ & 0.000 & 0.000 & $3.14^{* * *}$ & 0.000 \\
District & -2.704 & 0.705 & $-3.83^{* * *}$ & -0.589 \\
cons & -4.053 & 1.271 & -3.19 & \\
Number of obs & 172 & & & \\
LR chi2(10) & 133.25 & & & \\
Prob > chi2 & 0.000 & & & \\
Log likelihood & -52.597373 & & & \\
Pseudo R & 0.5588 & & & \\
\hline
\end{tabular}

*** and $* *$ indicate significance at 1 and $5 \%$ probability levels, respectively

Source: Own survey result, 2013

\subsection{Matching Member and Non-Member Households}

After propensity score estimation, the common support region should be mapped using propensity score distribution of member households and non-member households. Table 2 shows that the estimated propensity scores of member households vary from minimum value 0.0619 to a maximum value of 1.0000 with mean value of 0.8059 and for non-members between 3.40e-06 and 0.9360 with mean value 0.1922 . The common support region lies between 0.0619 and 0.9360 . This indicates that value less than 0.0619 and greater than 0.9360 were not considered for matching.

Table 2. Results of estimated propensity scores distribution

\begin{tabular}{llllll}
\hline Group & Obs & Mean & Std.Dev & Minimum & Maximum \\
\hline Total households & 172 & 0.4990 & 0.3947 & $3.40 \mathrm{e}-06$ & 1.0000 \\
Member households & 86 & 0.8059 & 0.2419 & 0.0619 & 1.0000 \\
Non-member households & 86 & 0.1922 & 0.2535 & $3.40 \mathrm{e}-06$ & 0.9360 \\
\hline
\end{tabular}

Source: Own survey result, 2013

\subsection{Choice of Matching Algorithm}

This paper used three different matching estimators to match the treatment and the control households (nearest neighbor, radius caliper and kernel matching). The final choice of a matching estimator was guided by three matching performance criteria such as balancing test, pseudo- $\mathrm{R}^{2}$ and matched sample size (Dehejia and Wahba, 2002). The first performance 
criteria is balancing test, which test whether there is a statistically mean significant difference of per-treatment characteristics of the two groups of the households, insignificant mean difference in all explanatory variables are preferred and also low Pseudo $\mathrm{R}^{2}$ and large matched sample size are preferred. Table 3 presents the estimated results of tests of matching the member and non-member households of Haramaya district. According to the result, nearest neighbor with replacement NN (4) is the best estimator as it that satisfies the above mentioned criteria.

Table 3. Results of different matching estimators

\begin{tabular}{|c|c|c|c|}
\hline \multirow[t]{2}{*}{ Matching estimators } & \multicolumn{3}{|c|}{ Performance criteria } \\
\hline & Balancing test & Pseudo- $\mathrm{R}^{2}$ & Matched sample size \\
\hline \multicolumn{4}{|l|}{ NN } \\
\hline $\mathrm{NN}(1)$ & 9 & 0.108 & 136 \\
\hline $\mathrm{NN}(2)$ & 9 & 0.072 & 136 \\
\hline $\mathrm{NN}(3)$ & 10 & 0.046 & 136 \\
\hline $\mathbf{N N}(4)$ & 10 & 0.036 & 136 \\
\hline $\mathrm{NN}(5)$ & 10 & 0.050 & 136 \\
\hline Caliper & & & 136 \\
\hline 0.1 & 9 & 0.108 & 136 \\
\hline 0.25 & 9 & 0.108 & 136 \\
\hline 0.5 & 9 & 0.108 & 136 \\
\hline Kernel & & & 136 \\
\hline Band width 0.1 & 10 & 0.045 & 136 \\
\hline band width 0.25 & 10 & 0.058 & 136 \\
\hline band width 0.5 & 9 & 0.083 & 136 \\
\hline
\end{tabular}

\subsection{Balancing of Propensity Score and Covariates Test}

This paper used three types of balancing tests to check the balance of the scores and covariates. First, we used two-sample t-test to check the significant different in the covariates of both members and non-member groups and calculated the standard bias before and after matching. After matching, we expected no significance difference between members and non-members. Secondly, we run a logit model using after-matching sample and compare the pseudo- $\mathrm{R}^{2}$ with $\mathrm{R}^{2}$ that obtained from logit estimation before matching sample. After matching the pseudo- $\mathrm{R}^{2}$ was low, this indicate there is no systematic difference in the distribution of covariates between both groups, therefore the balancing property is satisfied. Finally, we checked the balancing property by comparing the mean absolute standardized bias of members and non-members.

Before matching, seven variables were significantly different for the two groups which are experience on potato seed production, cultivated land holding, livestock holding, availability of social network, expectation of future potato seed price, availability of irrigation equipment and district dummy were statistically significant. However, after matching these significant covariates was balanced and became statistically insignificant (Table 4). According to all tests the matching algorithm that has chosen was relatively best. Therefore, we could continue to estimate ATT for the sample households. 


\section{Mll Macrothink}

Table 4. Balancing test of covariates

\begin{tabular}{llllllll}
\hline Variable & Sample & \multicolumn{3}{c}{ Mean } & \%bias & \% reduction bias & \multicolumn{2}{c}{ t-test } \\
\cline { 3 - 4 } \cline { 3 - 4 } & & Member & Non-member & & & t-value & P >/t/ \\
\hline _PSCORE & Unmatched & 0.839 & 0.166 & 273.1 & & $12.36^{* * *}$ & 0.000 \\
& Matched & 0.493 & 0.459 & 13.4 & 95.1 & 0.27 & 0.787 \\
SEX & Unmatched & 0.878 & 0.854 & 7.1 & & 0.32 & 0.750 \\
& Matched & 0.800 & 0.888 & -25.6 & -261.4 & -0.52 & 0.610 \\
EDU & Unmatched & 0.707 & 0.463 & 50.5 & & 1.25 & 0.125 \\
& Matched & 0.500 & 0.524 & -4.9 & 90.4 & -0.10 & 0.922 \\
FAMS & Unmatched & 7.098 & 6.293 & 32.6 & & 1.48 & 0.144 \\
& Matched & 6.800 & 6.917 & -4.7 & 85.5 & -0.11 & 0.912 \\
EXPR & Unmatched & 8.342 & 3.878 & 93.2 & & $4.22^{* * *}$ & 0.000 \\
& Matched & 7.000 & 6.025 & 20.4 & 78.2 & 0.51 & 0.615 \\
TLU & Unmatched & 4.698 & 1.925 & 153.4 & & $6.95 * * *$ & 0.000 \\
& Matched & 3.261 & 3.145 & 6.4 & 95.8 & 0.19 & 0.853 \\
TLH & Unmatched & 1.221 & 0.755 & 59.7 & & $2.70^{* * *}$ & 0.008 \\
& Matched & 0.916 & 1.003 & -11.2 & 81.3 & -0.23 & 0.819 \\
SOCN & Unmatched & 0.805 & 0.268 & 126.1 & & $5.71^{* * *}$ & 0.000 \\
& Matched & 0.600 & 0.563 & 8.700 & 93.1 & 0.16 & 0.875 \\
EXPEC & Unmatched & 1.073 & 0.902 & 47.4 & & $2.14^{* * *}$ & 0.035 \\
& Matched & 1.000 & 0.979 & 5.9 & 87.5 & 0.27 & 0.794 \\
IRREQ & Unmatched & 9761 & 2849 & 119.2 & & $5.42^{* * *}$ & 0.000 \\
& Matched & 6333 & 5522 & 14.0 & 88.3 & 0.28 & 0.780 \\
District & Unmatched & 0.712 & 0.423 & 50.5 & & $2.29 * *$ & 0.025 \\
& Matched & 0.500 & 0.449 & -4.9 & 95.4 & -0.10 & 0.922 \\
\hline
\end{tabular}

*** and ** indicate significance at 1 and $5 \%$ probability levels, respectively

\subsection{Estimating Average Treatment Effect on the Treated}

This section evaluated the impact of membership to potato seed producer cooperative on the livelihood of member households on the outcome variables (income from crop, income from livestock, total annual income, total expenditure and total asset). Estimation of average treatment effect was done by implementing nearest neighbor with replacement NN (4) after the distributions of member and non-member units were located in the same domain and the pre-intervention differences were controlled.

Table 5 shows the average treatment effect on the member households of both districts after controlling different pre-intervention characteristics like demographic, institutional and asset endowment of the member and non-member households. The result provides supportive evidence of statistically significant effect of potato seed producer cooperative on the livelihood of the sample households. This means, all outcome variables except income from livestock were statistically significant. Such as total annual income, income from crops including potato seed, total annuls expenditure and total assets were statistically significant.

In other word, members of potato seed producer cooperative have gained greater annual income by Birr 33901 (40\%) than non-member households and also members gain greater income from crop production by Birr 29006 (56\%). In addition, the total expenditure and total 
asset of member households were also greater by Birr 11728 (30\%) and Birr 47768 (45\%), respectively than non-member households.

Table 5. Estimation of average treatment effect (ATT) of outcome variables

\begin{tabular}{llllll}
\hline Outcome variable & Treated & Control & Different & S.E & t-value \\
\hline INCCR (BR) & 51495 & 22489 & 29006 & 11608 & $2.50^{* * *}$ \\
INCLV (BR) & 26678 & 25151 & 1527 & 4277 & 0.36 \\
ANINC (BR) & 84741 & 50839 & 33901 & 13653 & $2.48^{* * *}$ \\
TEXPEN(BR) & 39585 & 27856 & 11728 & 4498 & $2.61^{* * *}$ \\
TASSET(BR) & 106257 & 58488 & 47768 & 22004 & $2.17^{* *}$ \\
\hline
\end{tabular}

$* * *$ and $* *$ indicate significance at 1 and $5 \%$ probability levels, respectively

In Kersa district during the time of survey members of potato seed producer cooperative retained all their earnings in the bank. Seemingly, non-appropriations of the dividends, has influenced the results. This indicates the existence of insignificant difference between member and non-member in terms of the considered livelihood indicators.

\subsection{Sensitivity Analysis}

Sensitivity analysis after matching is important to check whether there is "hidden bias" or unobservable bias that affect ATT. PSM usually compare the difference between the outcome variables of members with non-members with similar essential characteristics and PSM only controls for selection bias that is specifically due to observable variables. However, it cannot correct unobservable bias. Therefore, if there are unobserved variables that simultaneously affect the participation decision and the outcome variables, a "hidden bias" or "selection on unobservable" bias might arise and the PSM estimator may no longer be consistent. According to Rosenbaum (2002), bounding approach was used to analyses sensitivity analysis. We analysed sensitivity analysis only for significant outcome variables, because sensitivity analysis for insignificant outcome variable is meaningless (Rosenbaum, 2002). Therefore, in this study income from livestock production was not considered for sensitivity analysis, because as mentioned above it was not statistically significant.

The sensitivity results shows that the inference of the effect of membership of potato seed producer cooperative is not changing though the member and non-member households have been allowed to differ in their odds of being treated up to $\mathrm{e}^{\gamma}=3$ in terms of unobserved covariates (Table 6). That means, the average treatment effect of the treated of each outcome variables were estimated at various levels of critical values of gamma, the p-critical values are not significant change, and this indicates there is no hidden bias due to unobserved confounder. Thus, the results suggest that the sensitivity analysis of the outcome ATT values were found to be insensitive or robust to unobserved selection bias. 
Table 6. Results sensitivity analysis

\begin{tabular}{llllll}
\hline Outcome variables & $\mathbf{e}^{\gamma}=\mathbf{1}$ & $\mathbf{e}^{\gamma}=\mathbf{1 . 5}$ & $\mathbf{e}^{\gamma}=\mathbf{2}$ & $\mathbf{e}^{\gamma}=\mathbf{2 . 5}$ & $\mathbf{e}^{\gamma}=\mathbf{3}$ \\
\hline INCCR & 0.0062 & 0.0207 & 0.1094 & 0.2529 & 0.4259 \\
ANINC & 0.0026 & 0.0563 & 0.2182 & 0.4351 & 0.6320 \\
TEXPEN & 0.0027 & 0.0575 & 0.2213 & 0.4393 & 0.6362 \\
TASSET & 0.0259 & 0.2153 & 0.5204 & 0.7587 & 0.8925 \\
\hline
\end{tabular}

Source: Own estimation results

Where: $e^{\gamma}$ (Gamma) is log odds of differential due to unobserved factors where Wilcoxon significance level for each significant outcome variable is calculated.

\section{Conclusion}

The aim of this paper is to examine the impact of potato seed cooperative on the livelihood of rural households. The impact estimation results shows that, after controlling the preintervention differences, it has been found that outcome variables such as: income from crop production, total annual income and total expenditure were statistically significant at $1 \%$ significance level and total assets was statistically significant at 5\% significance level. This means, members of potato seed producer cooperative have gained greater income from crop production and total annual income by Birr 29006 and 33901 respectively than non-member households. In addition, the total expenditure and total asset of member households were also greater by Birr 11728 and Birr 47768 respectively than non-member households.

The findings of this study also showed that a positive and statistically significant impact of potato seed producing cooperatives on the livelihood of rural households particularly in Haramaya district. The empirical evidence shows that the impact of potato seed producing cooperatives on the livelihood of member households in Kersa district was lower than Haramay district. Some of the potential reasons for this incongruence are households in Haramaya districts have better access to irrigation water, information, training, market and social network compared to Kersa district. In addition to member households, non-member households of both Haramaya and Kersa districts have been benefited from seed producing cooperatives. For instance, member households shared their experiences of seed production and sold quality seed with fair price to non-member households in the study areas. Therefore, the government and other non-government organization like ISSD should provide more support to expand potato seed producing cooperative and other activities to improve the livelihood of the rural households by increasing income and improving food security in the study area and the country as a whole.

\section{Acknowledgement}

The authors acknowledge the logistic support provided by Integrated Seed Sector Development (ISSD) at Haramaya University. 


\section{References}

Agricultural Transformation Agency (ATA). (2012). Agricultural Cooperatives Sector Development Strategy 2012-2016, June 2012. Addis Ababa, Ethiopia.

Amsalu, A., Afari-Sefa, V., Emana, B., Dinssa, F. F., Balemi, T., \& Temesgen, M. (2014). Analysis of Vegetable Seed Systems and Implications for Vegetable Development in the Humid Tropics of Ethiopia. International Journal of Agriculture and Forestry, 4(4), 325-337.

Bezabih, E. (2012). Cooperative Movement in Ethiopia. In Workshop on perspectives for Cooperatives in Eastern Africa.

Dawit, A. (2011). Farmer-Based Seed Multiplication in the Ethiopian Seed System: Approaches, Priorities \& Performance.

Dawit, A., Shahidur, S., \& Tripp, R. (2010). Seed System Potential in Ethiopia: Constraints and Opportunities for Enhancing the Seed Sector. IFPRI Working Paper, International Food Policy Research Institute.

Dehejia, R. H., \& Wahba, S. (2002). Propensity Score Matching Methods for NonExperimental Causal Studies: The Review of Economics and Statistics, 84(1), 151-161. https://doi.org/10.1162/003465302317331982

Fitsum, H., Gideon, K., Zenebe, A., Vincent, L., Afework, M., \& Girmay, G. S. (2006). Impact of small scale water harvesting on household poverty: evidence from Northern Ethiopia. Poverty Reduction and Environmental Management (PREM), 07/01.

Gujarat, D. N. (2004). Basic Econometrics. Tata McGraw Hill Book Company. New Delhi.

Heckman, J. J., Ichimura, H., Smith, J., \& Todd, P. (1997). Matching as an econometric evaluation estimator: evidence from evaluating a job training programme, The Review of Economic Studies, 64, 605-654. https://doi.org/10.2307/2971733

Hirpa, A., Meuwissen, M. P. M., Ivo, V. L., Lommen, W. J. M., Oude, L. A. G. J. M., Tsegaye, A., \& Struik, P. C. (2012). Farmers' opinion on potato seed management attributes in Ethiopia: a conjoint analysis. Agron. J., 104, 1413-1423. https://doi.org/10.2134/agronj2012.0087

Jalan, J., \& Ravallion, M. (2003). Estimating the benefit incidence of an antipoverty program by propensity-score matching. Journal of Business and Economics Statistics, 21(1), 19-30. https://doi.org/10.1198/073500102288618720

Minilek, A. (2012). The status of members' participation in seed producer and marketing cooperatives in Amhara Region, Bahirdar University, Bahirdar, Ethiopia.

MoARD (Ministry of Agriculture and Rural Development). (2002). Cooperative review, Addis Ababa, Ethiopia, 5.

Rosembaum, P. R., \& Rubin, D. B. (1983). The Central Role of the Propensity Score in Observational Studies for Causal effects, Biometrika, 70(1), 41-55. https://doi.org/10.1093/biomet/70.1.41 
Tadesse, K. (2006). Marketing smallholders' Coffee in Ethiopia: Does Market Reform Improve Producers' Share. Agricultural Economics Society of Ethiopia. Addis Ababa.

Veerakumaran, G. (2007). Ethiopian Cooperative Movement-an explorative study, Mekelle University.

\section{Copyright Disclaimer}

Copyright for this article is retained by the author(s), with first publication rights granted to the journal.

This is an open-access article distributed under the terms and conditions of the Creative Commons Attribution license (http://creativecommons.org/licenses/by/4.0/). 